\title{
EFFECT OF MICROSTRUCTURAL VARIATIONS ON THE TENSILE
}

\section{AND FRACTURE TOUGHNESS PROPERTIES OF ALLOY 718 WELDS}

\author{
William J. Mills \\ Westinghouse Electric Corporation \\ P.O. Bux 79 \\ West Mifflin, PA 15122
}

\begin{abstract}
The effect of microstructural variations on the tensile and fracture toughness properties of Alloy 718 welds is reviewed. The microstructural parameters surveyed include heat treatment, longterm thermal aging and neutron irradiation. The two heat treatments that were characterized include the conventional heat treatment, per ASTM B637, and a modified heat treatment designed to improve the toughness of Alloy 718. Both heat treatments resulted in room temperature yield strengths in excess of $1000 \mathrm{MPa}$ and total elongation values between 10 and $20 \%$. The fracture toughness of modified heat treated (MHT) welds was far superior to that for conventional heat treated (CHT) welds, which supports the use of the modified treatment when fracture resistance is a primary design concern. In the as-welded condition, welds exhibited moderate strength levels and good fracture properties that preclude fracture conccrns for most intermediate-strength applications. Fast-neutron irradiation significantly reduced ductility and fracture toughness for both heat treatments, but fracture resistance for the MHT weld was consistently higher than its CHT counterpart. Thermal aging at $566^{\circ} \mathrm{C}$ for times up to 20,000 hours resulted in a $10 \%$ increase in strength and two-fold reduction in ductility for both heat treated conditions. Longterm aging reduced the toughness of MHT welds by $25 \%$. The aged CHT welds showed tremendous variability in fracture resistance, with some specimens exhibiting a very brittle response. The mechanical properties were correlated with microstructural variations associated with thermal aging, irradiation and heat treatment.
\end{abstract}

\section{Introduction}

Alloy 718 is a high-strength nickel-base superalloy that exhibits good weldability and strain-age cracking resistance. Its superior welding characteristics are associated with the sluggish precipitation kinetics of the primary strengthening $\gamma^{\prime \prime}$ phase..$^{(1,2)}$ The sluggish hardening response results in a relatively high ductility fusion zone during cooling and aging. This permits relaxation of thermal and residual stresses and thereby improves strain-age cracking resistance. As a result of its good weldability, this alloy is used in the welded construction of components in the nuclear industry. Many of these components are highly loaded during service, so fracture control is an important design consideration. To assure the structural integrity of such components, a comprehensive understanding of the tensile and fracture responses for these welds is required. The effects of microstructural variations on the tensile and $\mathrm{J}_{\mathrm{IC}}$ fracture toughness properties for Alloy 718 gas-tungsten-arc welds were studied in a series of investigations conducted at Westinghouse Hanford Company, ${ }^{(3-6)}$ and the results are reviewed in this paper. The parameters surveyed include the effects of heat treatment, long-term thermal embrittlement and neutron irradiation. The heat treatments, described in Table 1, included the conventional heat treatment, per ASTM B637, and a modified heat treatment that was developed to improve the notch toughness of welds. $^{(7,8)}$ Tensile and fracture properties for the as-welded material are also summarized.

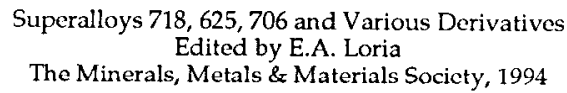


Table 1 Precipitation Heat Treatments

Conventional Heat Treatment (CHT), per ASTM B637

Solution annealed at $954^{\circ} \mathrm{C}$ for 1 hour and air cooled to room temperature

Aged at $718^{\circ} \mathrm{C}$ for 8 hours and furnace cooled at $55^{\circ} \mathrm{C} /$ hour to $621^{\circ} \mathrm{C}$

Aged at $621^{\circ} \mathrm{C}$ for a total aging time of 18 hours and air cooled to room temperature

Modified Heat Treatment (MHT)

Solution annealed at $1093^{\circ} \mathrm{C}$ for 1 hour and furnace cooled at $55^{\circ} \mathrm{C} /$ hour to $718^{\circ} \mathrm{C}$

Aged at $718^{\circ} \mathrm{C}$ for 4 hours and furnace cooled at $55^{\circ} \mathrm{C} /$ hour to $621^{\circ} \mathrm{C}$

Aged at $621^{\circ} \mathrm{C}$ for 16 hours and air cooled to room temperature

\section{Survey of Microstructural Variations}

\section{Effect of Heat Treatment}

The tensile properties between $24^{\circ}$ and $649^{\circ} \mathrm{C}$ for as-welded and heat-treated welds are summarized in Figure 1. The properties for the heat-treated welds are discussed first. Yield strength levels for the conventional heat treated (CHT) and modified heat treated (MHT) welds were independent of heat treatment and decreased by approximately $20 \%$ as temperature increased from $24^{\circ}$ to $649^{\circ} \mathrm{C}$. The strength levels were about $5 \%$ lower than those for CHT wrought metal and 5\% higher than those for MHT wrought metal, thereby demonstrating good overall compatibility between the base and weld metals.

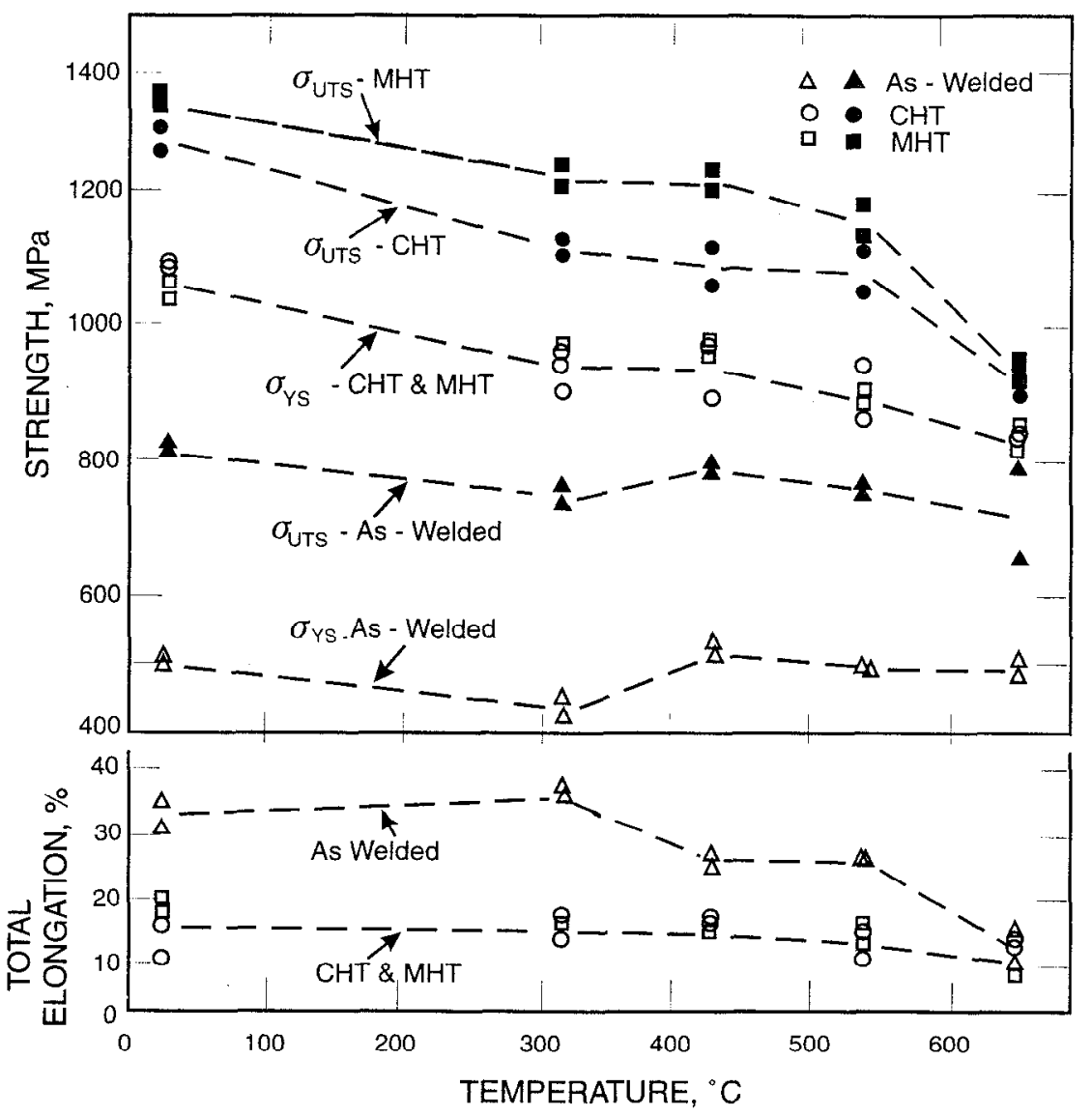

Figure 1. Effect of temperature on the $0.2 \%$ offset yield strength, ultimate strength (closed symbols) and total elongation. 


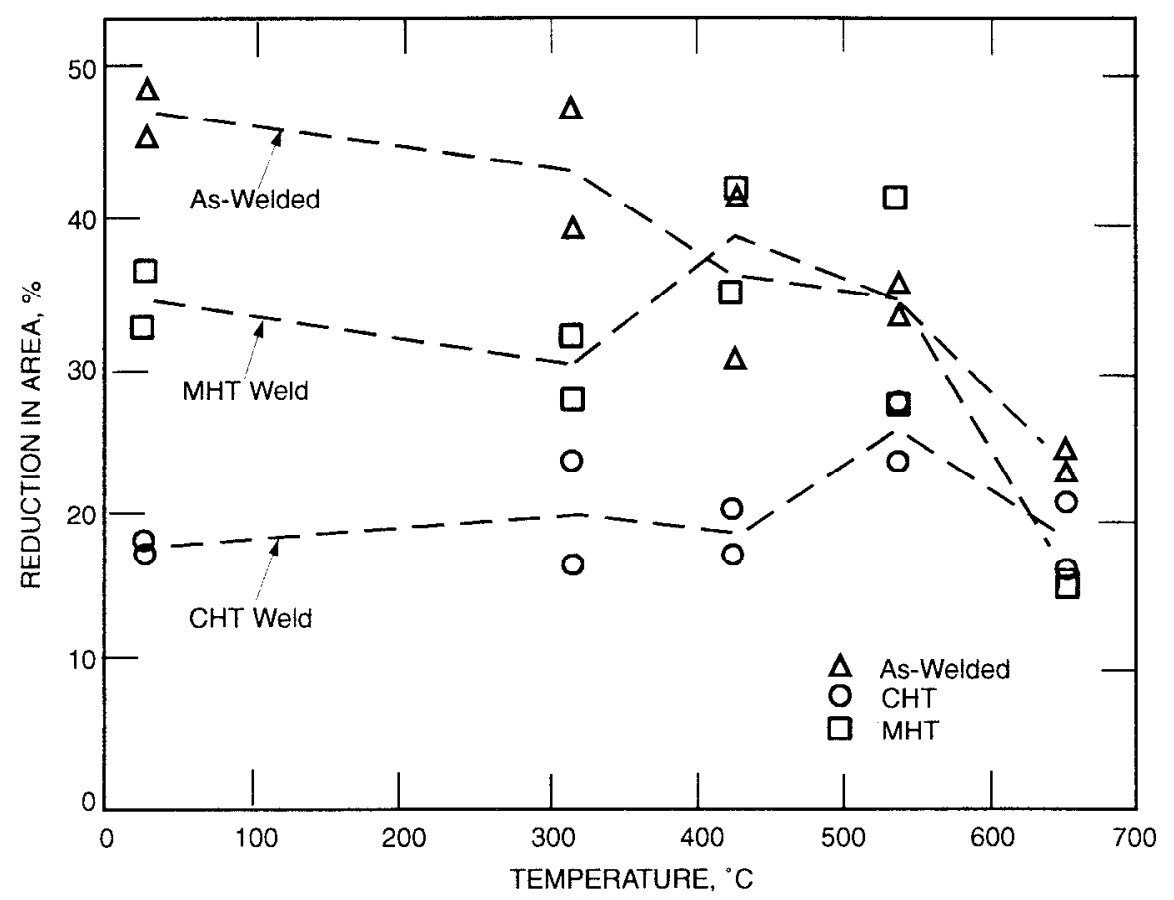

Figure 2. Effect of temperature on reduction in area.

Ultimate strength levels for MHT welds were $10 \%$ higher than those for CHT welds. In both heat treated conditions, ultimate strengths decreased by about $10 \%$ between $24^{\circ}$ and $316^{\circ} \mathrm{C}$, were independent of temperature between $316^{\circ}$ and $538^{\circ} \mathrm{C}$, and decreased by $15 \%$ between $538^{\circ}$ and $649^{\circ} \mathrm{C}$. Comparison of these strength values with those for wrought Alloy 718 revealed that MHT welds were 5 to $10 \%$ higher and CHT welds were $10 \%$ lower than those for their base metal counterparts.

Total elongation values for both heat-treated welds ranged from 10 to $20 \%$, regardless of test temperature. These ductility values were equivalent to those displayed by wrought Alloy 718 . (It is noted that uniform elongation values for all welds, including the as-welded condition, were only 1 to 3 percentage points less than the total elongations reported in Figure 1.) In contrast to the total elongation response, Figure 2 shows that reduction in area values for MHT welds were substantially higher than those for $\mathrm{CHT}$ welds at temperatures up to $538^{\circ} \mathrm{C}$. These results indicate that while the deformation characteristics for the two weld types are similar up to the onset of necking, significant differences in the deformation behavior occur once necking initiates. Specifically, MHT welds appear to be much more resistant to crack coalescence during the final stages of fracture, as discussed later.

Yield and ultimate strengths for the as-welded condition were approximately 30 to $50 \%$ lower than those for the heat-treated welds. Total elongation values were 2 to 3 times greater than for the age-hardened welds, except at $649^{\circ} \mathrm{C}$ where all welds exhibited the same ductility. Unlike the trends exhibited by heat treated welds, the as-welded strength was independent of temperature. Total elongation and reduction in area were reduced significantly with increasing temperature. Thermal aging of the weld during the $649^{\circ} \mathrm{C}$ tensile tests was responsible for the substantial reduction in ductility. Aging studies ${ }^{(3)}$ showed that a 1 hour exposure at $649^{\circ} \mathrm{C}$ increased the Rockwell $\mathrm{C}$ hardness from 24 to 30 , demonstrating that aging strengthened the matrix and reduced its ductility. The increased hardness offset the decrease in strength usually observed at $649^{\circ} \mathrm{C}$. It is noted that longer term aging at $649^{\circ} \mathrm{C}$ for 3,10 and 100 hours further increased the hardness to 35,37 and 42 , respectively. 


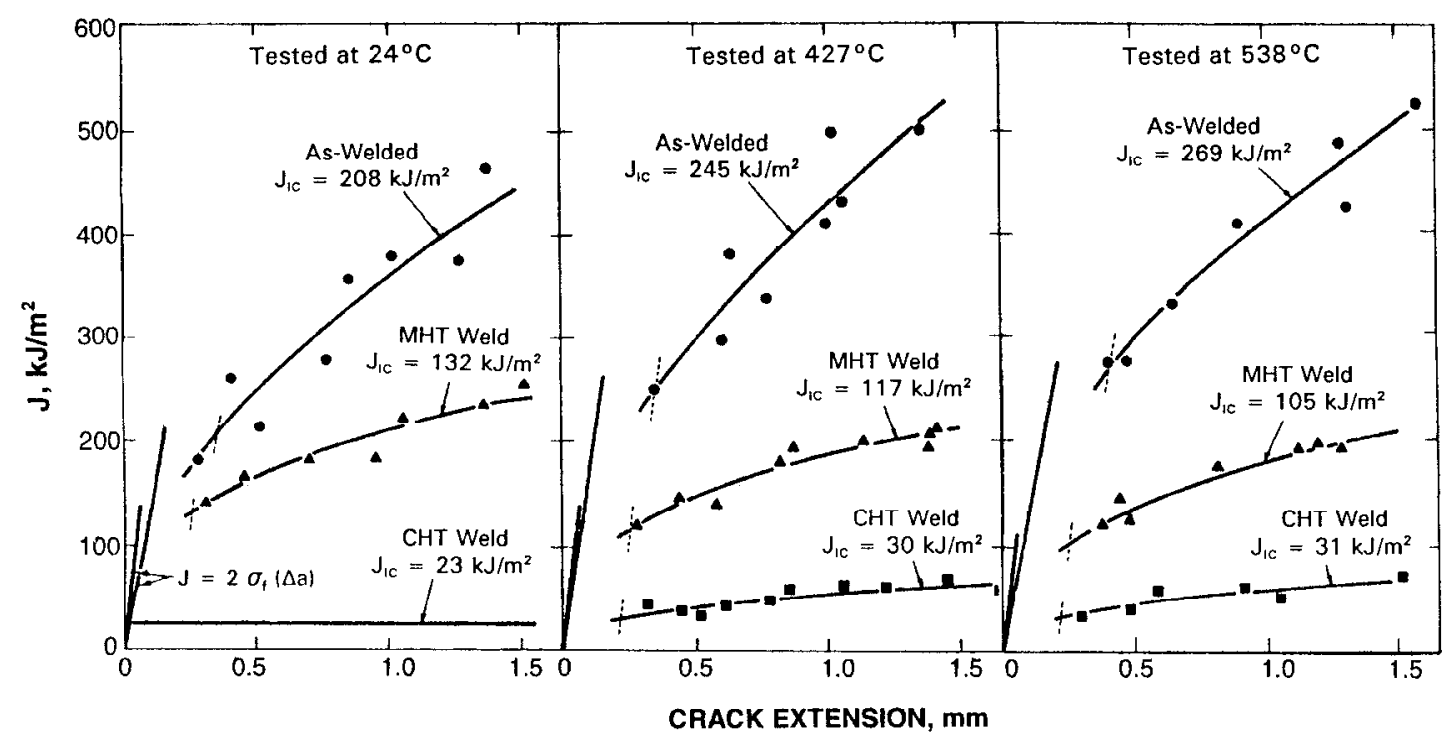

Figure 3. $J_{R}$ curves for as-welded, CHT and MHT welds tested at $24^{\circ}, 427^{\circ}$ and $538^{\circ} \mathrm{C}$.

The fracture resistance for the as-welded and heat-treated conditions at $24^{\circ}$ to $538^{\circ} \mathrm{C}$ is represented by the J-R curves shown in Figure 3, and the $\mathrm{J}_{\mathrm{IC}}$ values are summarized as a function of temperature in Figure 4. The CHT welds displayed the lowest fracture toughness at all temperatures. At $24^{\circ} \mathrm{C}$ failure occurred by unstable tearing at $\mathrm{K}_{\mathrm{TC}}$ levels of $68 \pm 5 \mathrm{MPa} V \mathrm{~m}$, which corresponds to a mean equivalent $J_{I C}$ value of $23 \mathrm{~kJ} / \mathrm{m}^{2}$. This behavior is represented in Figure 3 by the $J_{R}$ curve with a slope of zero. The fracture toughness for the CHT welds were slightly higher than the $55 \mathrm{MPa} \vee \mathrm{m}$ value reported by Forman ${ }^{(9)}$ and Lorenz ${ }^{(10)}$ for Alloy 718 welds containing surface cracks. At $427^{\circ}$ and $538^{\circ} \mathrm{C}$, CHT welds failed by stable tearing, but the fracture resistance remained very low with $J_{I C}$ values of 30 and $31 \mathrm{~kJ} / \mathrm{m}^{2}$.

The weld $\mathrm{J}_{\mathrm{IC}}$ values are compared with toughness values for wrought material ${ }^{(4)}$ in Figure 4. Previous studies showed that CHT and MHT wrought materials both exhibited systematic heat-toheat variations that were categorized into three distinguishable toughness levels. The mean $J_{I C}$ values for the lowest toughness wrought heats are represented by the broken lines on Figure 4 . Toughness values for the CHT weld are seen to be 30 to $50 \%$ lower than those for the least fracture resistant base metal, thereby demonstrating that the fracture resistance of the weld is limiting in CHT components.

MHT welds exhibited stable tearing and superior fracture properties, with $\mathrm{J}_{\mathrm{IC}}$ values ranging from 132 to $105 \mathrm{~kJ} / \mathrm{m}^{2}$ at $24^{\circ}$ to $538^{\circ} \mathrm{C}$, respectively. These values are not only $50 \%$ higher than those for the lowest toughness MHT base metal heats (broken line in Figure 4), they are slightly higher than the mean $\mathrm{J}_{\mathrm{IC}}$ values for base metal heats with intermediate toughness. As a result of their superior toughness, MHT welds are preferred over CHT welds for high strength applications when fracture is a primary design concern.

The as-welded material exhibited exceptional fracture resistance. In addition to the high $\mathrm{J}_{\mathrm{IC}}$ values, which ranged from 208 to $269 \mathrm{~kJ} / \mathrm{m}^{2}$ at $24^{\circ}$ to $538^{\circ} \mathrm{C}$, the tearing resistance was very high, as evidenced by the steep $\mathrm{J}_{\mathrm{R}}$ curves. These results show that the as-welded material has sufficient toughness to preclude fracture concerns for low and intermediate-strength applications.

The differences in mechanical properties were correlated with microstructural variations associated with the different weld conditions. Representative microstructures, metallographic profiles of fracture surfaces and fracture morphologies for the three weld types are shown in Figures 5, 6 and 7 , respectively. In the as-welded condition, Laves phase, a topologically-close-packed phase, formed in the interdendritic regions enriched in niobium content. Although Laves particles are 


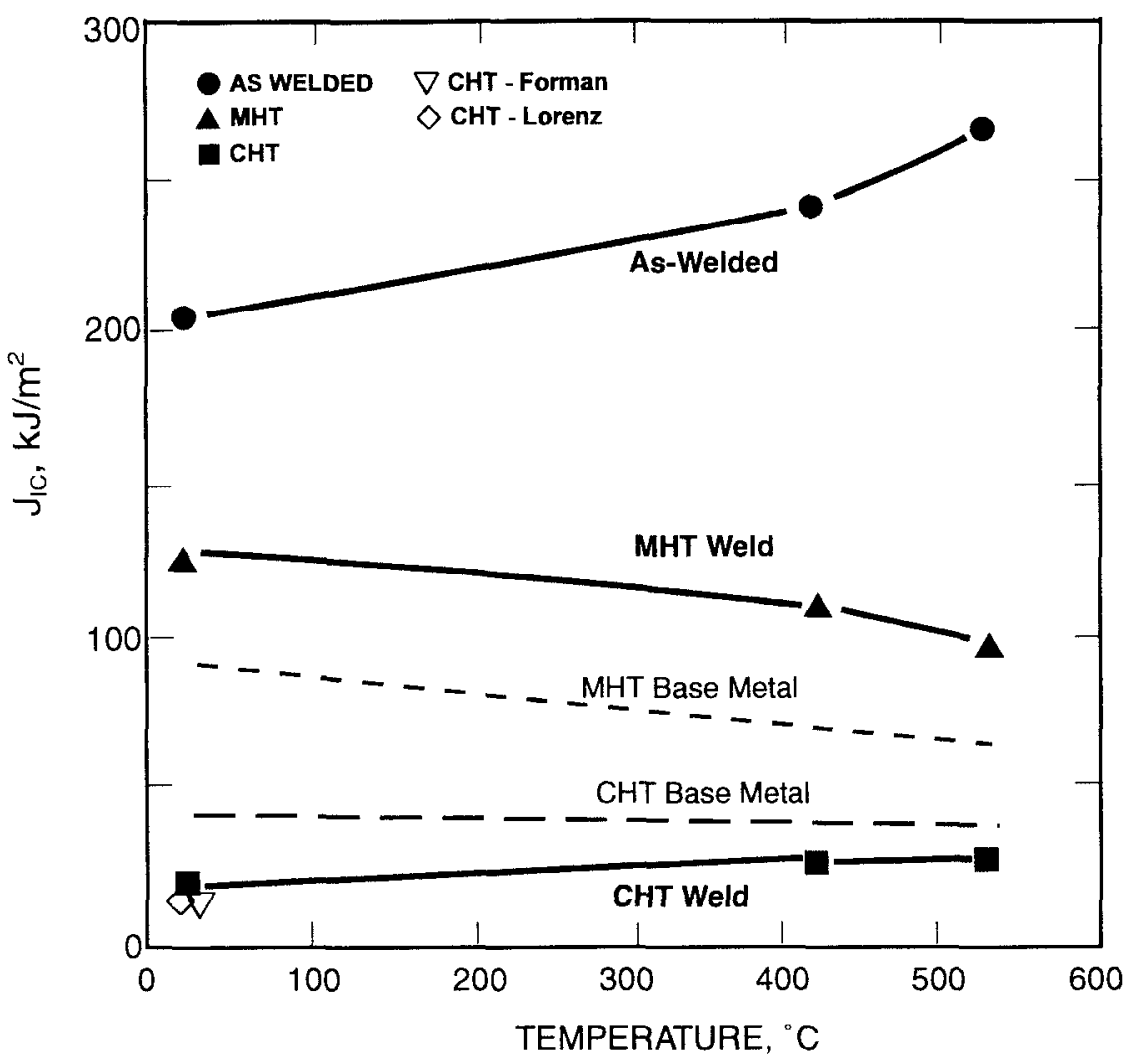

Figure 4. Summary of $\mathrm{J}_{\mathrm{IC}}$ results for Alloy 718 welds. Broken lines represent the mean $\mathrm{J}_{\mathrm{IC}}$ values for the lowest toughness heats of wrought Alloy 718.

brittle and serve as microvoid nucleation sites, they did not degrade the ductility of the unaged weld because the matrix had sufficient fracture resistance to arrest the microcracks emanating from the broken particles. In fact, the fracture-resistant matrix accommodated broken Laves particles at a significant distance from the crack plane in fracture toughness specimens and throughout the entire gage length of tensile specimens, as shown in Figure 6a. Final fracture occurred as these microcracks coalesced, resulting in well-defined dimples that were often aligned in rows, as shown in Figures $7 \mathrm{a}$ and $7 \mathrm{~b}$. These observations demonstrate that the excellent fracture resistance of the nickel matrix accounts for the superior ductility and fracture toughness of the as-welded material at temperatures up to $538^{\circ} \mathrm{C}$. The loss of ductility at $649^{\circ} \mathrm{C}$ was attributed to aging of the matrix which increased strength but significantly reduced ductility.

As shown in Figure $5 b$, CHT welds exhibited blocky Laves phase surrounded by needle-like $\delta$ precipitates, an orthorhombic $\mathrm{Ni}_{3} \mathrm{Nb}$ phase. The CHT annealing temperature of $954^{\circ} \mathrm{C}$ was not high enough to dissolve the Laves particles and it caused $\delta$ particles to precipitate in the $\mathrm{Nb}$-rich regions. These particles, which did not contribute to the strength due to their coarse size, served as local crack initiation sites. In contrast to the as-welded behavior, however, the high streng"? CHT matrix had low fracture resistance that could not arrest microcracks nucleated by the seccond phase particles. Thus, once microvoids nucleated they quickly coalesced resulting in an overall advance of the macroscopic crack before other particles further away from the crack plane could fail. This explains the overall absence of failed Laves and $\delta$ particles outside the primary fracture plane, as illustrated in Figure $6 \mathrm{~b}$. The fracture surfaces exhibited rows of shallow and ill-defined dimples (Figures $7 \mathrm{c}$ and $7 \mathrm{~d}$ ) that initiated at Laves and $\delta$ particles. The poorly defined dimple structure, reminiscent of a tearing topography surface, ${ }^{(11)}$ resulted from the high density of microvoid nucleation sites coupled with the high strength matrix that suppressed plastic flow and limited void growth. The high density of second phase particles coupled with the low fracture- 

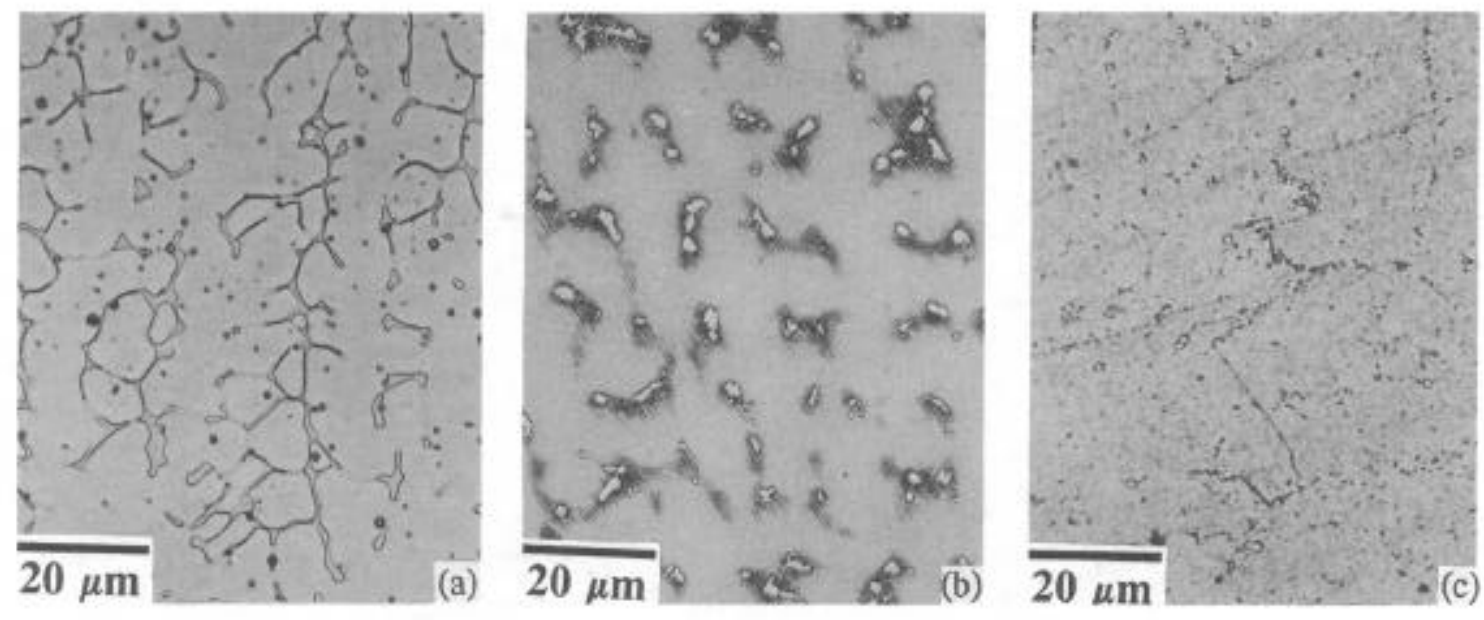

Figure 5. Representative weld microstructures. (a) As-welded. (b) CHT. (c) MHT.
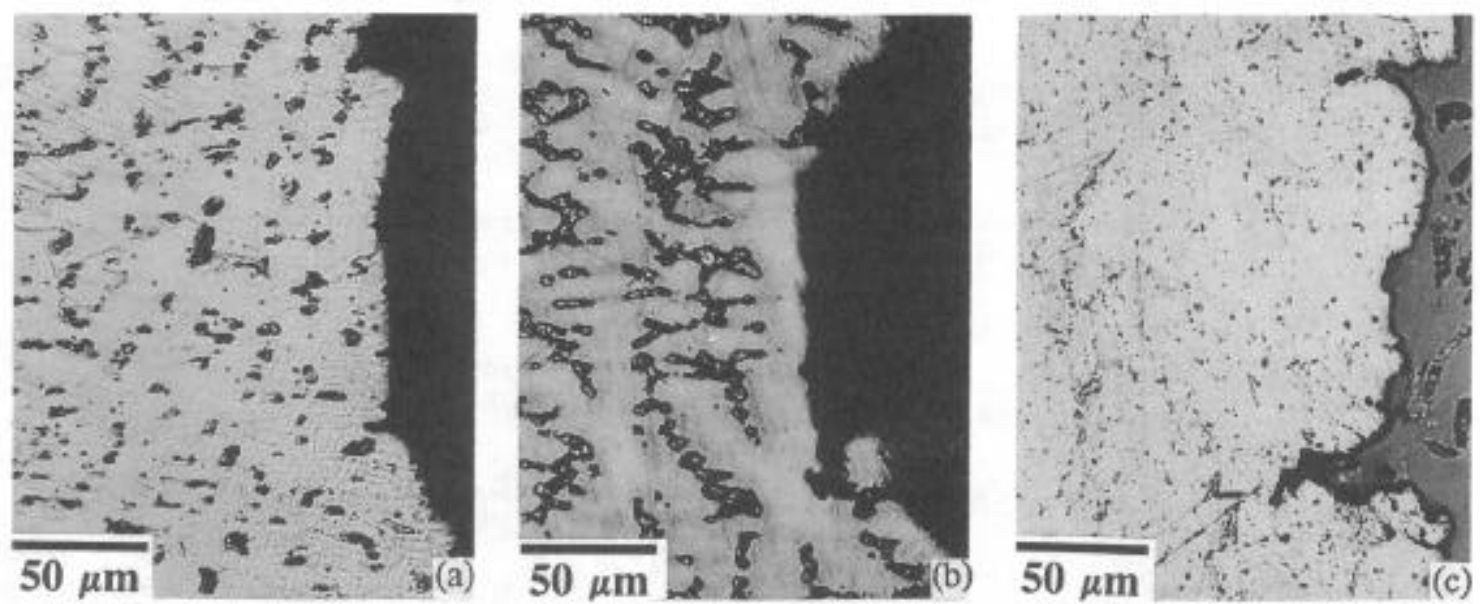

Figure 6. Metallographic profiles of fracture surfaces. (a) As-welded. (b) CHT. (c) MHT.

resistant matrix resulted in poor ductility and fracture toughness.

Figures $5 \mathrm{c}$ and $6 \mathrm{c}$ show that the $1093^{\circ} \mathrm{C}$ MHT anneal drastically reduced the amount of Laves phase and caused significant homogenization of the interdendritic structure. Only traces of Laves particles and carbides remained in the weld zone. Fracture surfaces of the MHT weld contained well defined, equiaxed dimples that were nucleated by the carbides and Laves phase remnants (Figures $7 \mathrm{e}$ and $7 \mathrm{f}$ ). These small second phase particles were resistant to fracture and generally failed by decohesion at the particle/matrix interface. Additional plastic deformation was required for microvoid nucleation and coalescence due to reduced particle density and enhanced fracture resistance of the relatively small carbides and Laves particles. This accounts for the drastic improvement in reduction in area and fracture toughness for the MHT welds.

\section{Effect of Long-Term Thermal Aging}

The effect of aging at $566^{\circ} \mathrm{C}$ on the tensile properties for CHT and MHT welds at $538^{\circ} \mathrm{C}$ is summarized in Figure 8. Exposure for more than 5000 hours caused only a $5 \%$ increase in yield and ultimate strength levels and a decrease in total elongation of about 6 percentage points.

The fracture toughness of heat treated welds aged at $566^{\circ} \mathrm{C}$ for 5000 to 20,000 hours is shown in Figure 9. The CHT welds showed tremendous scatter after aging, which precluded construction of meaningful $\mathrm{J}_{\mathrm{R}}$ curves. After aging for 5000 hours, the fracture resistance for half 


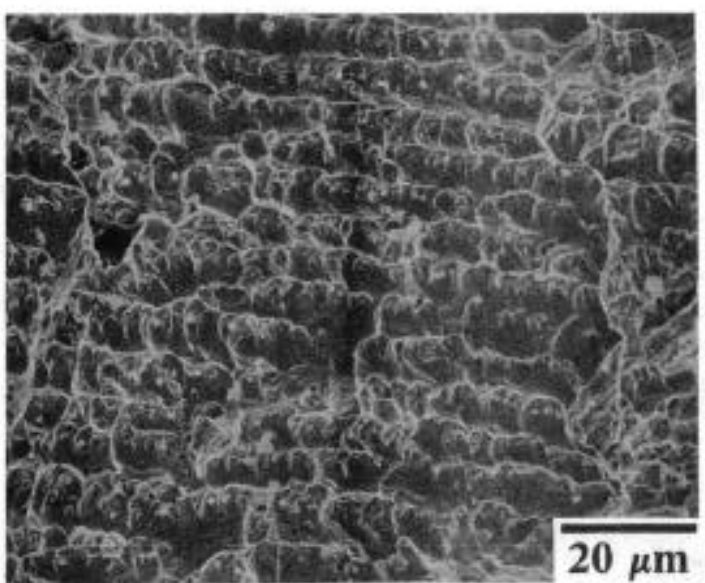

(a)

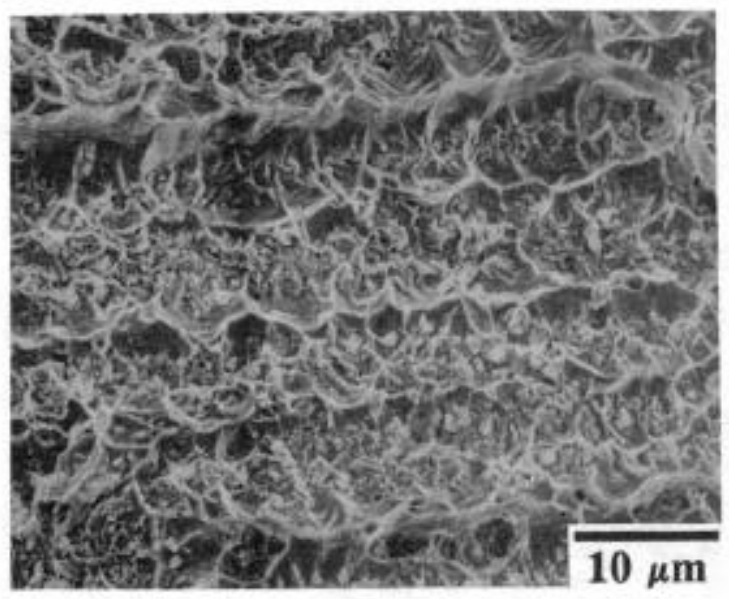

(c)

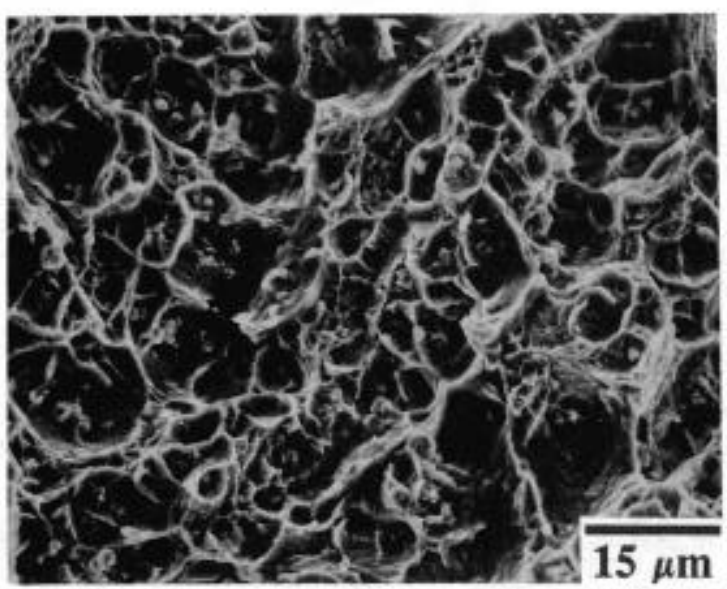

(e)

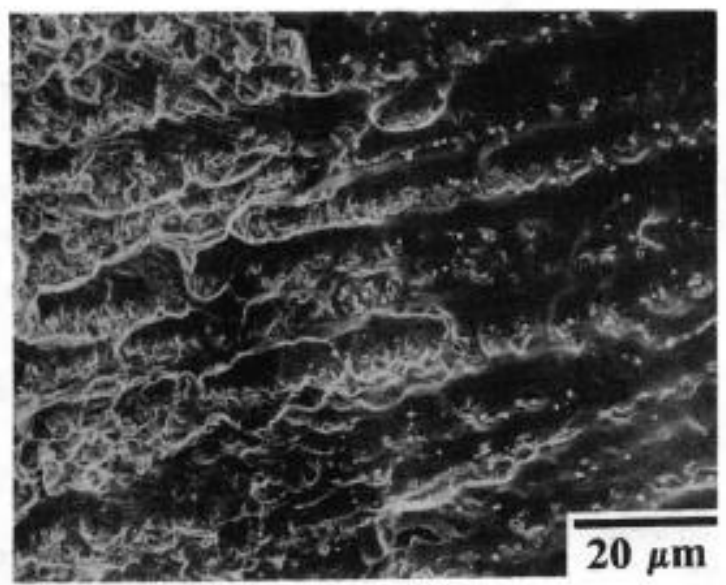

(b)

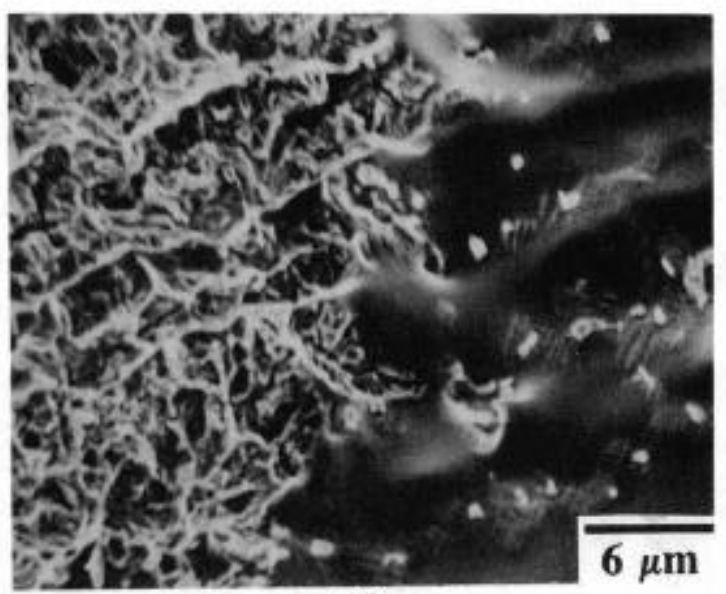

(d)

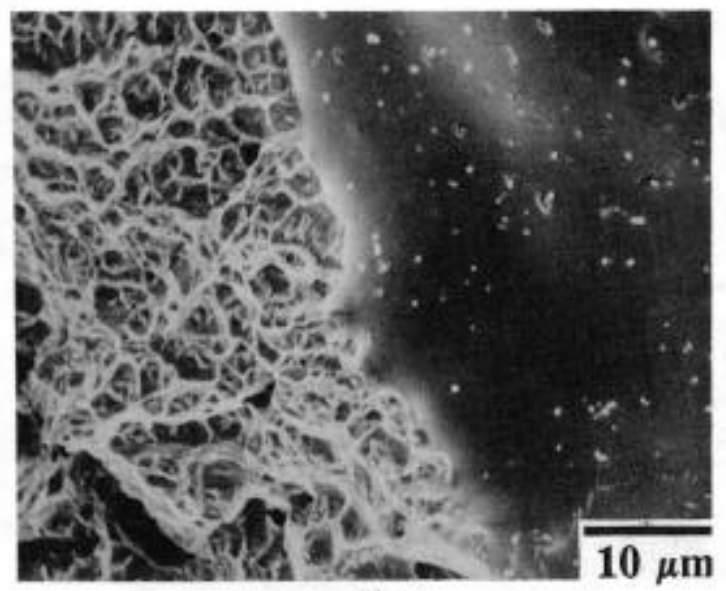

(f)

Figure 7. Electron micrographs showing typical fracture surface morphology and metallographic-fractographic profiles. (a) (b) As-welded. Well-defined dimples nucleated by Laves phase. (c) (d) CHT. Poorly defined dimples, reminiscent of a tearing topography surface, nucleated by high density of Laves and $\delta$ particles. (e) (f) MHT. Equiaxed dimples nucleated by carbides and Laves phase remnants. 


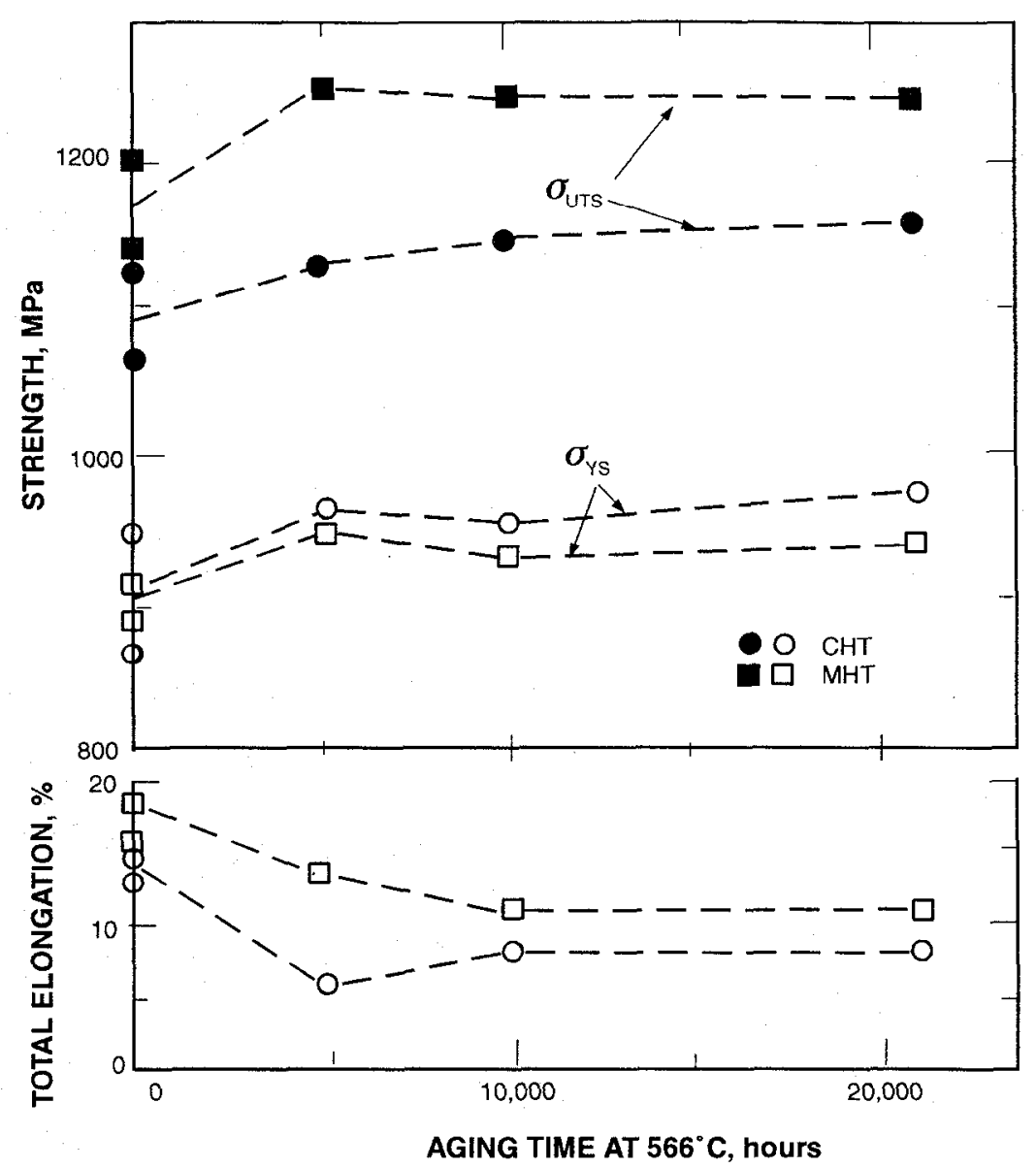

Figure 8. Effect of long-term thermal aging on the $0.2 \%$ offset yield strength, ultimate strength (solid symbols) and total elongation at $538^{\circ} \mathrm{C}$.

of the specimens was significantly improved, whereas the other half showed a substantial degradation (ie, three specimens had $\mathbf{J}$ values that were $40 \%$ higher than the corresponding $\mathrm{J}$ values for unaged CHT weld, while the other three had values that were $40 \%$ lower). This variability was reflected in the amount of plastic deformation in the load-displacement curves. After 10,000 and 20,000 hours of exposure, approximately half of the specimens showed little or no net change in fracture resistance, while the others exhibited a brittle, plane strain fracture toughness response, with ASTM valid $\mathrm{K}_{\mathrm{IC}}$ values of $55 \pm 7 \mathrm{MPa} V \mathrm{~m}$.

The large scatter was due to aging-induced microstructural variability. Exposure at $566^{\circ} \mathrm{C}$ partially dissolved the blocky Laves particles, but increased the size and density of $\delta$ particles, as shown in Figure 10a. The reduced size of the Laves phase tended to increase toughness, while the increased size and density of $\delta$ platelets resulted in a large degradation in toughness. Nucleation and growth kinetics of the $\delta$ phase varied significantly from specimen to specimen. For the 5000-hour aged specimens with high toughness (Figure 11a), there was some dissolution of the Laves phase, but the aging time was insufficient to increase $\delta$ platelet density. For the low toughness specimens (Figure 11b), the 5000-hour exposure induced significant $\delta$ precipitation that degraded fracture resistance.

The kinetics of $\delta$ precipitation also dictated the fracture response after 10,000 and 20,000 hour exposures. Some specimens showed only a modest increase in $\delta$ phase density. This tended to cause a slight reduction in toughness that was offset by the partial dissolution of Laves particles. 


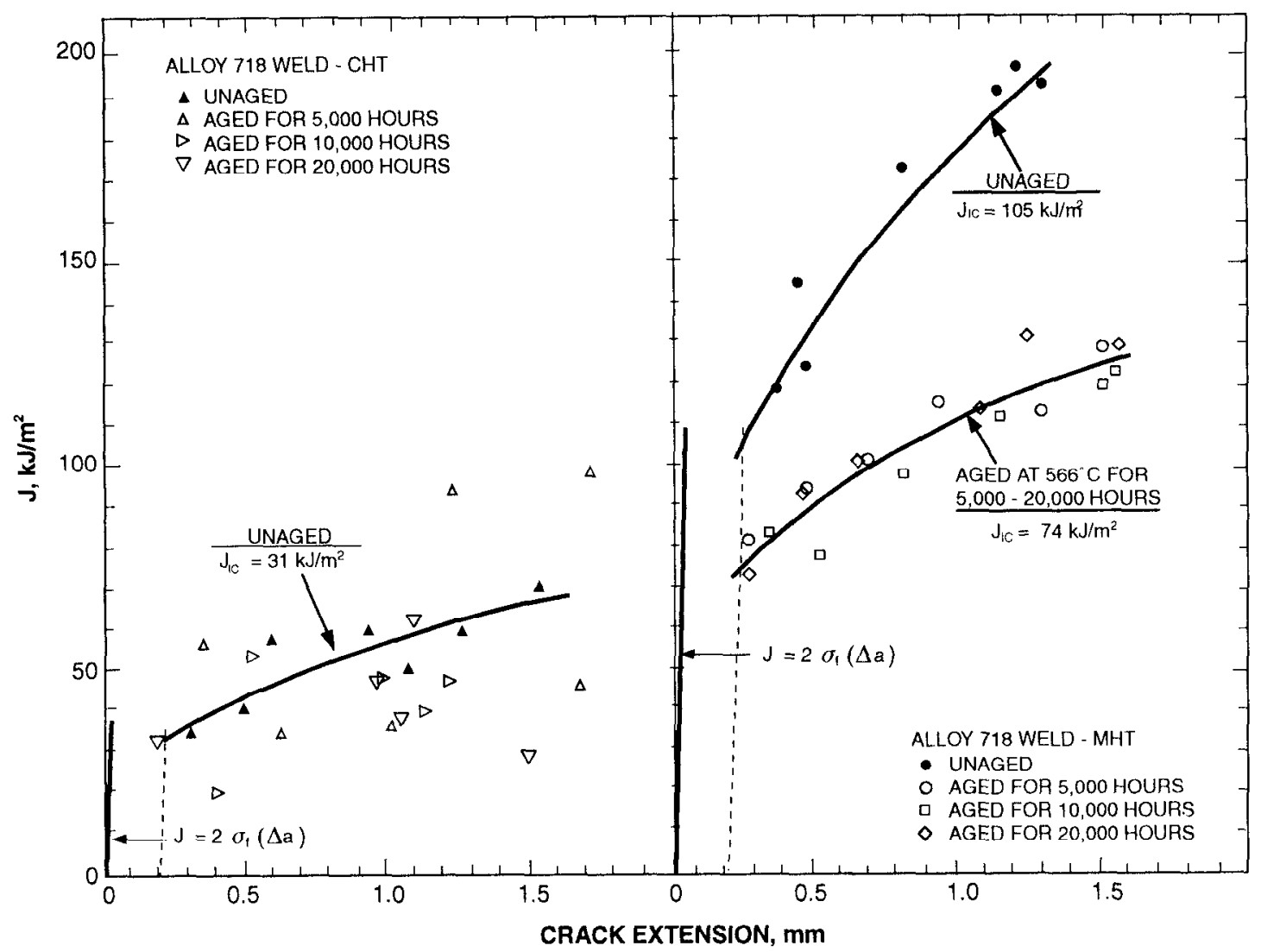

Figure 9. Effect of long-term thermal aging on the fracture toughness at $538^{\circ} \mathrm{C}$.

The net result was essentially no change in toughness in comparison to the as-heat treated welds. Specimens exhibiting a brittle response displayed large $\delta$ platelet colonies that initiated large microvoids (Figure 11a). These microvoids easily coalesced causing a premature advance of the crack and ultimately resulting in brittle fracture.

Figure 9 shows that the toughness for MHT welds aged for 5000 to 20,000 hours was the same, demonstrating that the aging-induced degradation in toughness saturated prior to 5000 hours. As a result, all data for aged MHT welds were combined into a single $J_{R}$ curve that yielded a $J_{I C}$ value of $74 \mathrm{~kJ} / \mathrm{m}^{2}$. Long-term aging is seen to cause a $25 \%$ reduction in $\mathrm{J}_{\mathrm{IC}}$ and a significant degradation in tearing resistance, as indicated by the lower $J_{R}$ curve slope. Nevertheless, the MHT weld retains good fracture resistance that was superior to that for the CHT welds in the asheat treated or aged condition.

The reduced toughness for the MHT welds was associated with $\delta$ precipitation during aging at $566^{\circ} \mathrm{C}$, as shown in Figure $10 \mathrm{c}$. In the aged condition, both the $\delta$ platelets and Laves remnants served as microvoid nucleation sites (Figure $11 \mathrm{~d}$ ) and thereby reduced fracture resistance. Note that the toughness of the aged MHT welds, $74 \mathrm{~kJ} / \mathrm{m}^{2}$, was essentially the same as the mean $J_{\mathrm{IC}}$ value of $76 \mathrm{~kJ} / \mathrm{m}^{2}$ for the high toughness CHT wrought heats that also contained a relatively low density of $\delta$ platelets. ${ }^{(4)}$

\section{Effect of Neutron Irradiation}

The effect of high irradiation exposures on the tensile properties at the irradiation temperature of $427^{\circ} \mathrm{C}$ is shown in Figure 12. Irradiation to $10 \mathrm{dpa}$ increased the yield and ultimate strength levels for the CHT weld by only about $5 \%$, but at 28 dpa they were reduced to the unirradiated levels. Postirradiation elongation values, which ranged from 5 to $7 \%$, were independent of 

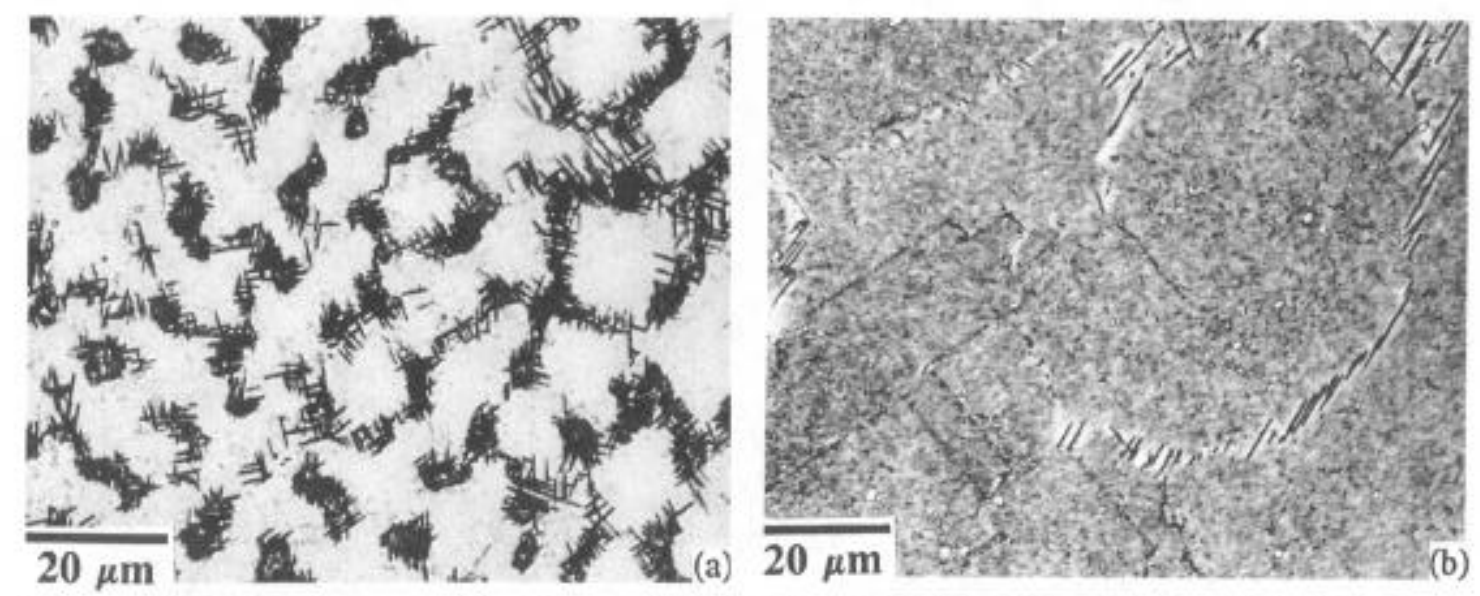

Figure 10. Microstructure of welds aged at $566^{\circ} \mathrm{C}$. (a) CHT. Note colonies of $\delta$ platelets. (b) MHT. Limited evidence of intergranular and intragranular $\delta$ particles.
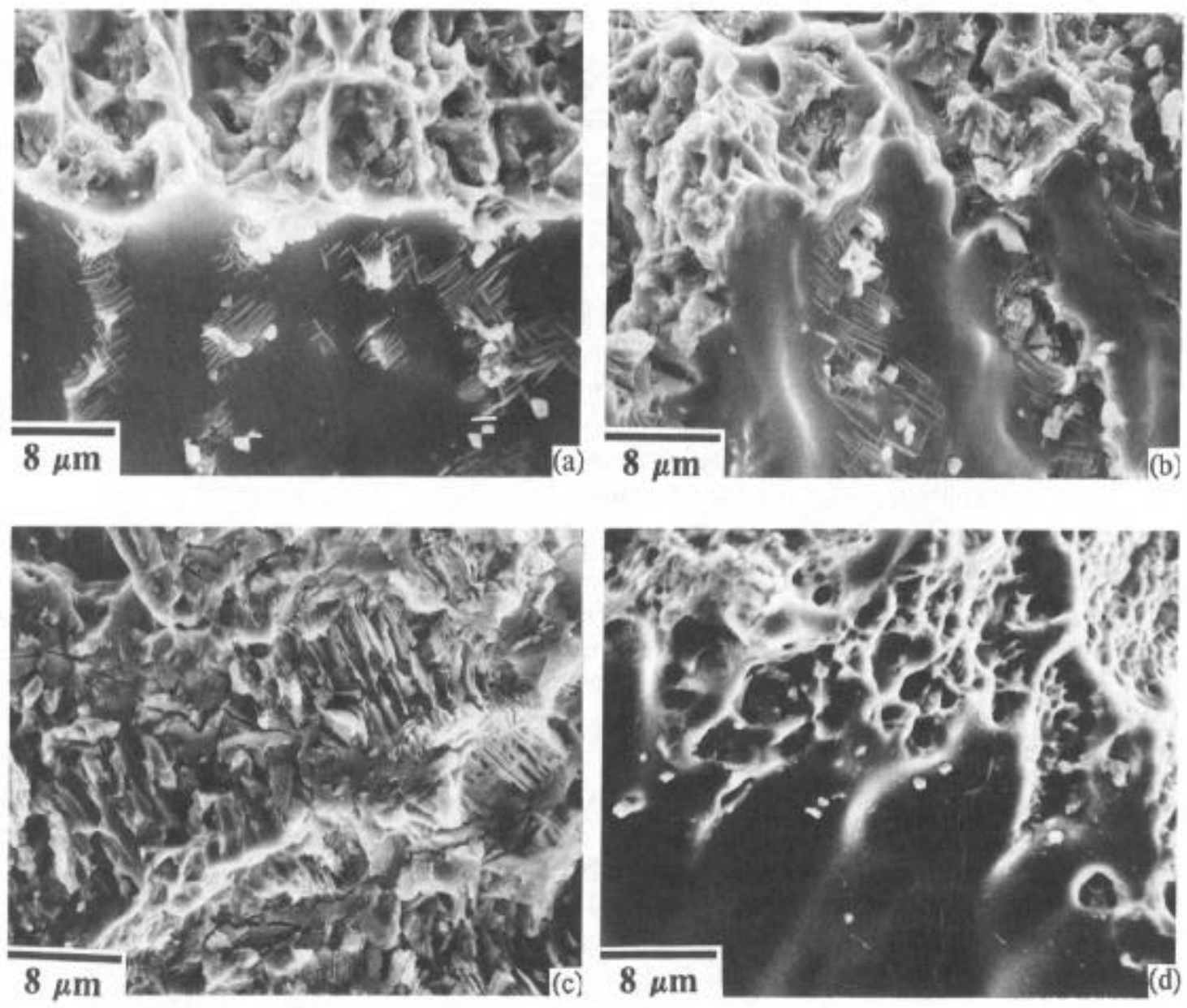

Figure 11. Metallographic-fractographic profiles and fracture surface appearance of welds aged at $566^{\circ} \mathrm{C}$. (a) High toughness CHT weld aged for 5000 hours showing low density of $\delta$. (b) Low toughness CHT weld aged for 5000 hours showing high density of $\delta$. (c) Large dimples nucleated by $\delta$ colonies in aged CHT weld. (d) Dimples nucleated by carbides, Laves remnants and sparce $\delta$ precipitates in aged MHT weld. 

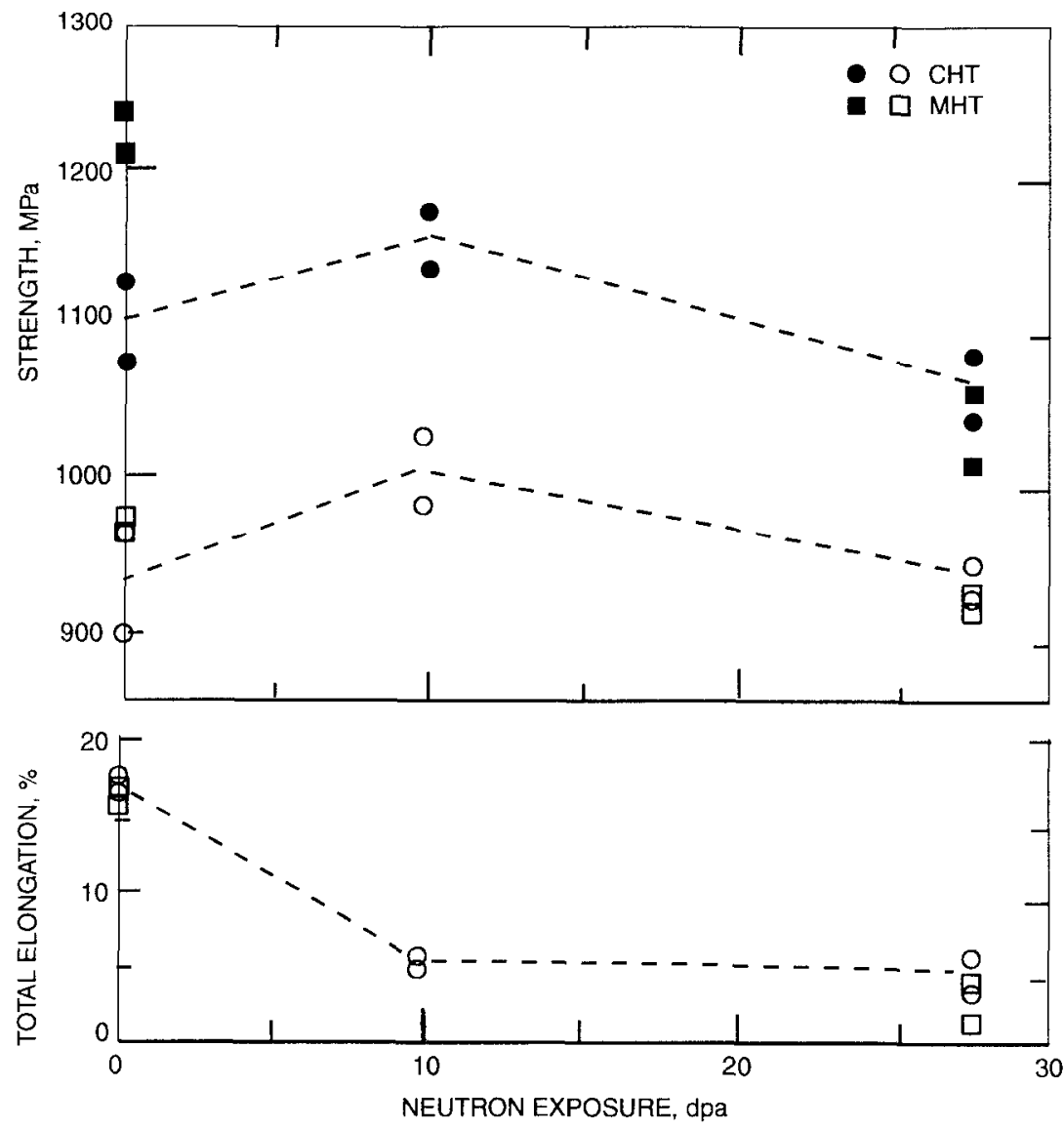

Figure 12. Effect of irradiation on $0.2 \%$ yield strength, ultimate strength (solid symbols) and total elongation at $427^{\circ} \mathrm{C}$.

exposure, indicating that the loss in ductility saturated prior to $10 \mathrm{dpa}$. The MHT weld was only tested at 28 dpa where its tensile properties were comparable to those for the CHT weld.

The postirradiation $J_{R}$ curves at $427^{\circ} \mathrm{C}$, shown in Figure 13 , showed that irradiation caused a substantial degradation in toughness. At exposures ranging from 8 to $28 \mathrm{dpa}$, fracture properties were independent of irradiation dose. This demonstrated that irradiation embrittlement saturated prior to reaching these exposures, as shown in Figure 14. High neutron exposures reduced the $\mathrm{J}_{\mathrm{IC}}$ values from 30 to $20 \mathrm{~kJ} / \mathrm{m}^{2}$ for CHT welds and from 117 to $53 \mathrm{~kJ} / \mathrm{m}^{2}$ for MHT welds. Although MHT welds showed the larger percentage reduction in toughness, its postirradiation $\mathrm{J}_{\mathrm{IC}}$ was still more than double that for CHT welds. Figure 14 also shows that the saturation toughness for the MHT weld was slightly higher than its base metal counterpart, whereas the CHT weld displayed a lower saturation toughness relative to the CHT base metal.

The highly irradiated CHT welds failed by a channel fracture mechanism (Figure 15a), associated with local failure along intense planar slip bands. Specifically, the lead dislocations swept out the irradiation-induced lattice defects which created defect-free channels that were weaker than the surrounding matrix. As a result, subsequent dislocation activity was confined to these channels and eventually shear cracks initiated and propagated along them. This low energy fracture mechanism resulted in the poor postirradiation fracture resistance displayed by CHT welds. Close examination of the fracture surface revealed that the channel fracture morphology was extremely well defined and the facets were often aligned along the dendritic structure. The well-developed planar facets show that an intense heterogeneous slip mechanism was operative, 


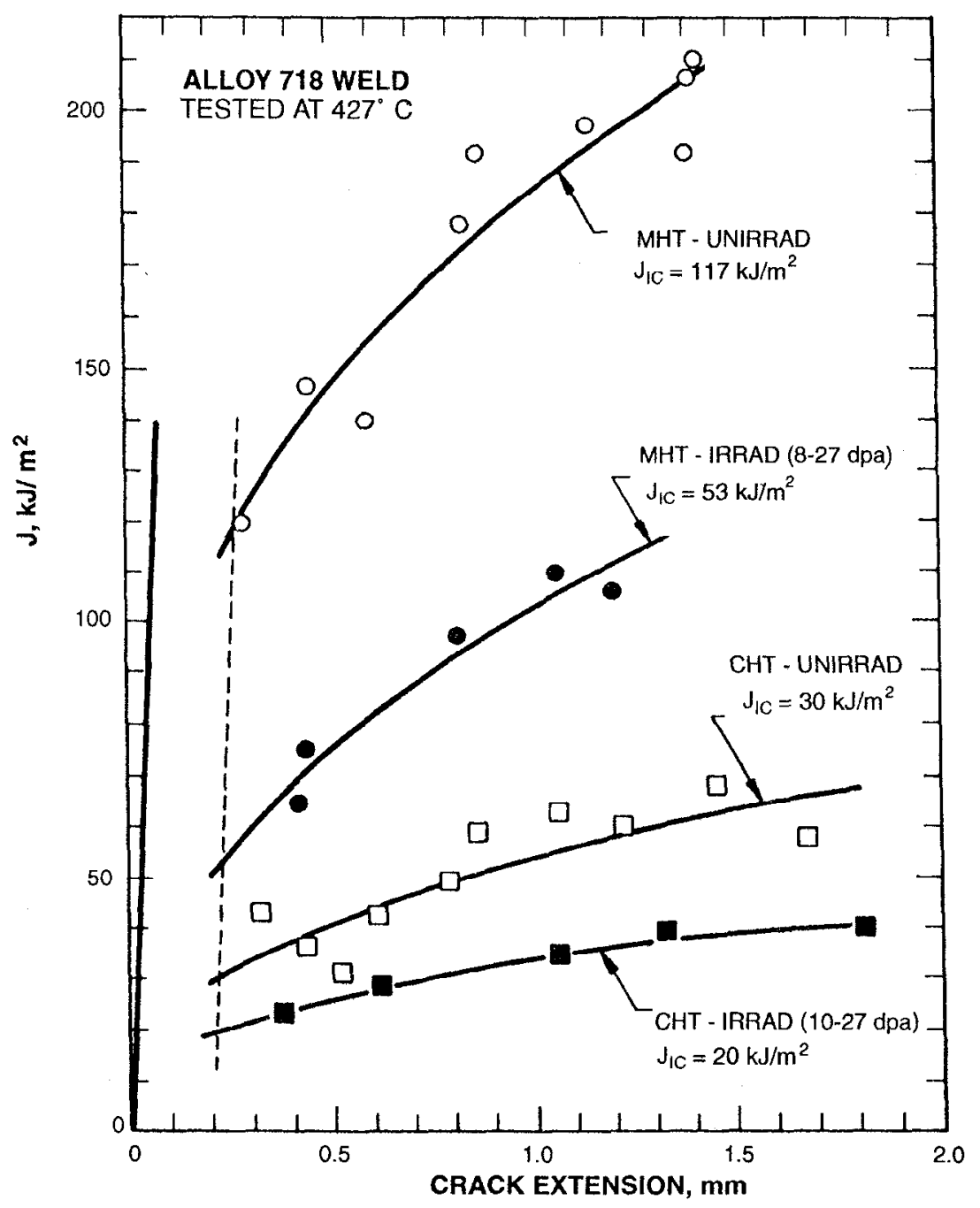

Figure 13. Effect of irradiation on fracture toughness of CHT and MHT welds at $427^{\circ} \mathrm{C}$.

and the absence of Laves and $\delta$ precipitates on the fracture surface indicates that the dislocation channels were confined to the regions between the interdendritic particles.

The irradiated MHT welds displayed a combination of channel fracture and shallow dimples, as shown in Figure 15b. Although the dimples were poorly defined, their presence demonstrated that the matrix possessed limited homogeneous deformation capabilities. Additional support for a limited homogeneous slip mechanism was the ill-defined channel fracture facets, contrasting the well-developed facets in the irradiated CHT welds. The increased homogeneous slip capabilities in the MHT weld accounts for its superior postirradiation fracture resistance.

\section{CONCLUSIONS}

The effects of microstructural variations on the tensile and fracture properties of Alloy 718 welds were reviewed and the conclusions are presented below.

1. While tensile properties for the heat-treated welds were relatively insensitive to heat treatment, the fracture toughness was markedly affected by heat treatment. Fracture resistance for the MHT weld was far superior to that for its CHT counterpart. This supports the use of the modified heat treatment when fracture is an important design consideration. In the as-welded condition, the relatively low strength weld exhibited excellent ductility and 


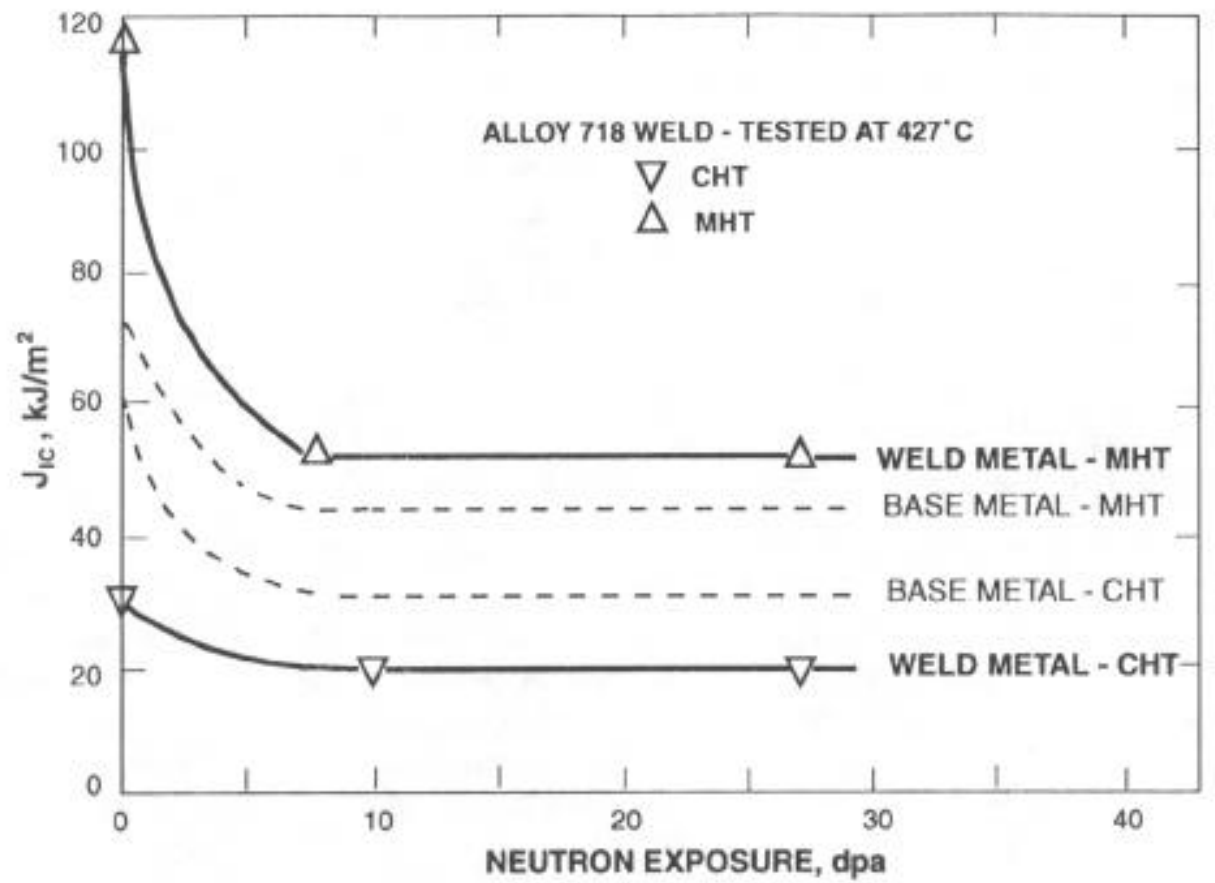

Figure 14. $\mathrm{J}_{\mathrm{IC}}$ values for irradiated Alloy 718 weld metal and base metal.

fracture toughness, so fracture is not a primary concern.

2. The poor fracture properties for the CHT weld resulted from a combination of a matrix with low fracture resistance and a high density of Laves and $\delta$ particles that served as effective microvoid nucleation sites. The $1093^{\circ} \mathrm{C}$ MHT anneal greatly reduced the size and density of coarse particles and thereby increased fracture properties without sacrificing strength. The fracture-resistant matrix in the as-welded condition accommodated microvoids nucleated by broken Laves particles in the fusion zone. As a result, extensive plastic deformation was required to coalesce the microvoids, which accounts for its excellent ductility and toughness.

3. Long-term aging at $566^{\circ} \mathrm{C}$ had very little effect on strength, but caused a two-fold decrease in ductility in CHT welds. It also dramatically increased the variability in fracture toughness
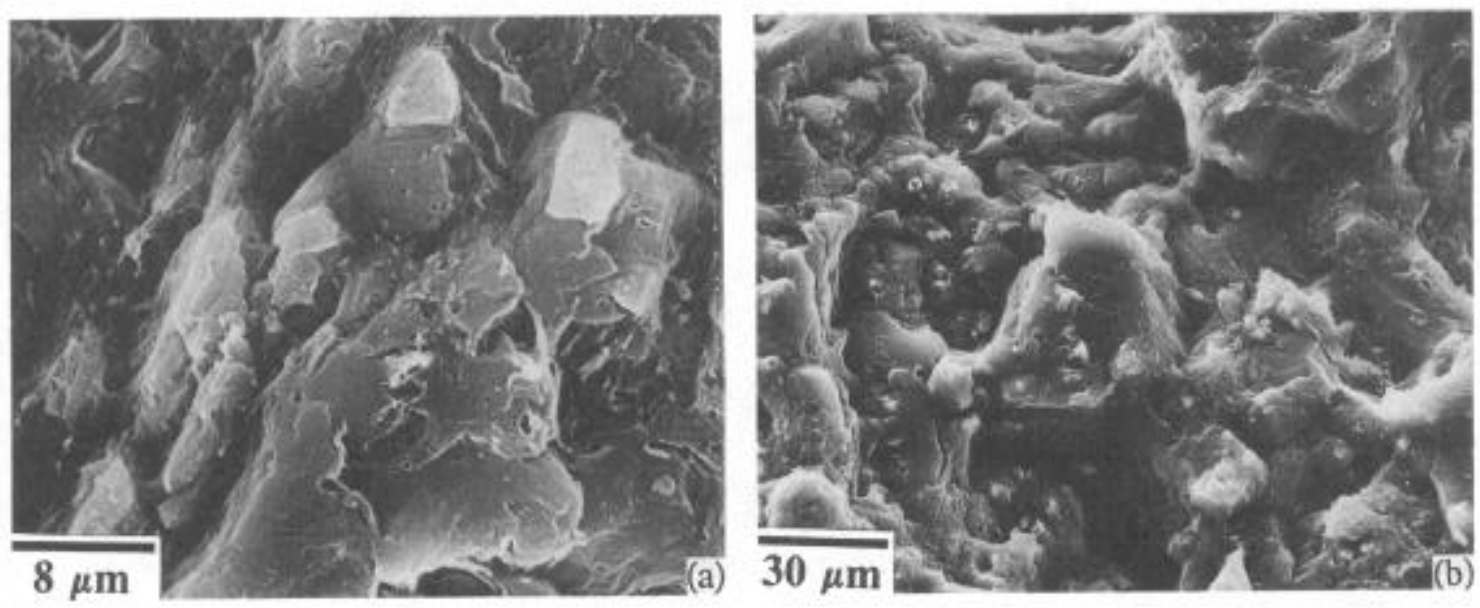

Figure 15. Fracture surface appearance for irradiated welds. (a) CHT weld showing welldefined channel fracture. (b) MHT weld showing ill-defined channel fracture facets and shallow dimples. 
for the CHT welds. Some specimens exhibited improved fracture resistance, relative to the unaged condition, whereas other specimens displayed a very brittle response with $\mathrm{K}_{\mathrm{IC}}$ values as low as $48 \mathrm{MPa} / \mathrm{m}$. This large data scatter was associated with variability in precipitation kinetics. Aging at $566^{\circ} \mathrm{C}$ increased the amount of $\delta$, which decreased toughness, but reduced the size of Laves phase, which increased toughness. Hence, the Laves phase dissolution rate versus the $\delta$ precipiation rate determined the toughness response. The density of $\delta$ varied significantly from specimen to specimen, and those with high concentrations displayed inferior toughness.

4. Aging at $566^{\circ} \mathrm{C}$ degraded $\mathrm{J}_{\mathrm{IC}}$ for the MHT weld by $25 \%$, but the resulting toughness was still 2.5 times that for the unaged CHT weld. The reduction in toughness resulted from aginginduced $\delta$ precipitates that served as microvoid initiation sites.

5. Neutron irradiation exposures from 8 to 28 dpa reduced the toughness to saturation $\mathrm{J}_{\mathrm{IC}}$ values of 20 and $53 \mathrm{~kJ} / \mathrm{m}^{2}$ for the CHT and MHT welds, respectively. Channel fracture dominated the fracture surface in the CHT weld, which indicates that an irradiation-induced transition from homogeneous to heterogeneous slip was responsible for its low fracture resistance. The irradiated MHT weld displayed a combination of channel fracture and ill-defined dimples. The latter mechanism indicates that limited homogeneous slip processes were operative, which accounts for the superior postirradiation toughness of the MHT weld.

\section{REFERENCES}

1. Prager, M. and Shira, C. S., "Welding of Precipitation-Hardening Nickel-Base Alloys," Welding Research Council Bulletin No. 128, 1968.

2. Duvall, D. S. and Owczarski, W. A., "Studies of Postweld Heat-Treatment Cracking in Nickel-Base Alloys," Welding Journal, 48 (1969), 10s-22s.

3. Mills, W. J., "Effect of Heat treatment on the Tensile and Fracture toughness Behavior of Alloy 718 Weldments," Welding Journal, 63 (1984), 237s-245s.

4. Mills, W. J., "Fracture Toughness Variations for Alloy 718 Base Metal and Welds," Superalloy 718--Metallurgy \& Applications (Warrendale, PA: The Metallurgical Society, 1989), 517-532.

5. Mills, W. J., "Fracture Toughness of Thermally Aged Alloy 718 Weld Metal," Welding Journal, 66 (1987), 113s-119s.

6. Mills, W. J., "Effect of Irradiation on the Fracture Toughness of Alloy 718 Plate and Weld," Journal of Nuclear Materials, 199 (1992), 68-78.

7. Smolik, G. R. and Reuter, W. G., "Heat Treatment Versus Properties Studies with Inconel 718 PBF Acoustic Filters," Technical Report No. 493, Aerojet Nuclear Company, Idaho Falls, ID, 1975.

8. Reuter, W. G., "Design Data for the $1 / 4$ in. Thick Alloy 718 In-Pile Tube," Report TREENUREG-1087, EG\&G Idaho, Inc., Idaho Falls, 1977.

9. Forman, R. G., "Crack-Growth Behavior in Thick Welded Plates of Inconel 718 at Room and Cryogenic Temperatures," Report NASA TN-D7665, Lyndon B. Johnson Space Center, Houston, Texas, 1974.

10. Lorenz, P. M., "Effect of Pressurized Hydrogen Upon Inconel 718 and 2219 Aluminum," Report NASA CR-100208, Jet Propulsion Laboratory EG-479375 and University of California, and Boeing Company, Seattle, Washington.

11. Thompson, A. W. and Chesnutt, J. C., "Identification of a Fracture Mode: The Tearing Topography Surface," Metallurgical Transactions, 10A (1979), 1193-1196. 